\title{
Rescuing of deficient killing and phagocytic activities of macrophages derived from non-obese diabetic mice by treatment with geldanamycin or heat shock: potential clinical implications
}

\author{
Virginia Loreto Vega • Wisler Charles • \\ Laura E. Crotty Alexander
}

Received: 8 February 2011 /Revised: 3 May 2011 / Accepted: 5 May 2011 /Published online: 29 May 2011

(C) Cell Stress Society International 2011

\begin{abstract}
Diabetes mellitus type 1 (DMT1) is an autoimmune disease characterized by the destruction of insulinproducing cells in the pancreas. Diabetic patients are more susceptible to recurrent and uncontrolled infections, with worse prognoses than in healthy individuals. Macrophages $(\mathrm{M} \phi \mathrm{s})$ derived from DMT1 individuals have compromised mounting of inflammatory and immune responses. The mechanisms responsible for these alterations remain unknown. It has been shown that the presence of extra- and intracellular heat shock proteins (hsp) positively modulates immune cell function. Using naive M $\phi$ s derived from nonobese diabetic (NOD) mice, a well-established mouse model for DMT1, we demonstrate that heat shock (HS) as well as treatment with geldanamycin (GA), significantly improves diabetic $\mathrm{M} \phi$ activation, resulting in increased phagocytosis and killing of bacteria. Induction of HS did not affect the aberrant NOD-M $\phi$ cytokine profile, which is characterized by elevated IL-10 levels and normal tumor necrosis factor alpha. Our observations were consistent at pre-diabetic (normal random blood glucose) and diabetic (random blood glucose greater than $250 \mathrm{mg} / \mathrm{dl}$ ) stages, suggesting that HS and GA treatment may compensate for intrinsic genetic alterations present in diabetic cells regardless of the stage of the disease. The mechanisms associated
\end{abstract}

\footnotetext{
V. L. Vega $(\triangle) \cdot$ W. Charles

Department of Surgery, University of California San Diego,

9500 Gilman Drive, \#0739,

La Jolla, CA 92093-0739, USA

e-mail: vvega@ucsd.edu

L. E. C. Alexander

Department of Pediatrics, University of California San Diego,

La Jolla, CA, USA
}

to this phenomenon are unknown, but they may likely be associated with the induction of hsp expression, a common factor between HS and GA treatment. Our results may open a new field for non-classical function of hsp and indicate that hsp expression may be used as a part of therapeutic approaches for the treatment of complications associated with DMT1 as well as other autoimmune diseases.

Keywords Bacteria $\cdot$ Internalization $\cdot$ Diabetes mellitus type 1. Glucose

\section{Introduction}

Heat shock protein (hsp) expression constitutes the most primitive mechanism for cellular protection. This function is accomplished due to the proteins' intracellular chaperone activity and is responsible for the refolding of stressdenatured proteins and stabilization of transcription and translation (Lindquist and Craig 1988; Morimoto 1991; De Maio 1999). More recently, it has been shown that hsp also regulate other cellular activities such as cytoskeleton rearrangement (Han et al. 2000; Kirby et al. 1994; Liao et al. 1995; Dou et al. 2003; Lavoie et al. 1993; Piotrowicz and Levin 1997), endocytosis and phagocytosis (Vega et al. 2010; Vega and De Maio 2005), and activation of immune cells (Vega et al. 2008; Asea et al. 2000, 2002). Especially interesting is the capacity of both extra- and intracellular hsp to regulate the immune system by activation of key cells such as macrophages (M $\phi \mathrm{s})$ and dendritic cells, thereby controlling inflammatory and immune responses (Vega et al. 2010; De Maio 2010; Asea et al. 2000, 2002; Basu et al. 2001). The mechanisms associated with this 
activation remain unknown, but it has been proposed that they are part of the stress response (SR). Thus, hspmediated immune activation may constitute a primary signal to activate and control the inflammatory process resulting in faster destruction of pathogens, clearance of necrotic and apoptotic cells (AC), activation of healing mechanisms, and homeostasis restoration. In agreement with this, induction of hsp in several clinical conditions, such as ischemia/reperfusion, infections, respiratory distress, hemorrhage, and diabetes, has been observed (Donnelly et al. 1992; De Maio 1999; Giffard et al. 2008; Villar et al. 1993). Among these conditions, diabetes and, more specifically, diabetes mellitus type 1 (DMT1) represents an interesting scenario for a potential modulatory effect of hsp, particularly since functional and developmental defects of professional phagocytes have been associated with the initiation and progression of this autoimmune disease (Bagley et al. 2008; Hutchings et al. 1990; Jun et al. 1999; Maree et al. 2005; Gordon and Taylor 2005).

In the USA alone, an estimated 2 million people have been diagnosed with DMT1, while worldwide, the incidence of this disease continues to increase rapidly (by $2-5 \%$ per year). DMT1 is the second most common chronic disease diagnosed in children. The only definitive treatment for DMT1 is a pancreatic transplant, which is only performed in patients who have advanced disease because it is a highly complicated and risky procedure. Similarly, there are no successful strategies for the treatment of the underlying inflammatory process responsible for the destruction of $\beta$ cells in the pancreas as well as prevention of DMT1 development in susceptible individuals. Aggressive treatment of diabetes and factors contributing to diabetes can delay and possibly prevent the development of serious complications, such as heart disease, kidney failure, nerve damage, and recurrent infections. The current treatment for DMT1, which in the USA alone has reached a cost of $\$ 40$ billion per year, involves subcutaneous administration of insulin with careful attendance to both exercise and nutrition. It is well accepted that the initiation and the progression of DMT1 is linked to intrinsic dysfunction in professional phagocytes (i.e., M $\phi$ s), which results in a compromised mounting of immune and inflammatory responses (Fan et al. 2004; Shultz et al. 1995; O'Brien et al. 2006; Trudeau et al. 2000; Marée et al. 2008; Mohammad et al. 2006). For example, it has been shown that deficient internalization of $\mathrm{AC}$ by M $\phi$ s derived from diabetic individuals is accompanied by decreased production of IL-10 and increased secretion of pro-inflammatory cytokines, generating an unusual pro-inflammatory environment in response to $\mathrm{AC}(\mathrm{O}$ 'Brien et al. 2006; Trudeau et al. 2000; Marée et al. 2008; Mohammad et al. 2006). On the contrary, incubation of DMT1-derived M $\phi$ s with pro-inflammatory stimuli has been shown to produce unusually high levels of $\mathrm{PGE}_{2}$, which leads to down-regulation of cellular immune activation and therefore a decrease in inflammation (Benhamou et al. 1995). Clinically, DMT1 patients are more susceptible to the development of recurrent and more severe infections than non-diabetic individuals (Pozzilli and Leslie 1994). Inflammatory processes in DMT1 patients are the most common cause of glucose imbalance, hospitalization, limb amputation, wound healing delay, and/or potentially fatal consequences. Thus, priority has been given to the development of clinical or pharmacological interventions that improve regulation of inflammation in diabetic patients. In this study, we characterize the inflammatory and immune responses of naive $\mathrm{M} \phi \mathrm{s}$ derived from non-obese diabetic (NOD) mice, a well-established animal model for DMT1, and the effect of heat shock (HS) and GA treatment on their response to pro-inflammatory stimuli.

\section{Results and discussion}

Mфs derived from NOD mice have decreased phagocytic and killing activities in comparison with cells derived from non-diabetic strains Professional phagocytes, such as M $\phi \mathrm{s}$, are widely distributed cells. Genetic and environmental factors that affect their responses have been linked to the pathogenesis of DMT1, although the exact mechanisms remain unknown (Fan et al. 2004; Shultz et al. 1995). It has been suggested that deficient internalization and/or clearance of $\mathrm{AC}$ by M $\phi$ s may be linked to the development of autoimmunity (O'Brien et al. 2006; Trudeau et al. 2000; Marée et al. 2008; Mohammad et al. 2006). Both AC and pathogens are internalized by phagocytosis, although the cell surface receptors involved in these processes are different. Therefore, we hypothesize that the clinically reported high incidence of infections in diabetic patients is due to deficient clearance of pathogens, secondary to an impaired inflammatory response. To evaluate this possibility, we compared bacteria (Staphylococcus aureus and Escherichia coli) phagocytic capacity of two populations of naive M $\phi s$, alveolar (AM $\phi s$ ) and peritoneal (PM $\phi s) \mathrm{M} \phi s$, derived from female ( 8 weeks old) non-obese diabetic (NOD/ShiLtJ) mice with cells isolated from non-diabetic strains (BALB/c, C57BL6 [B6] and Swiss mice). All mice were purchased from Jackson Laboratories (Bar Harbor, ME, USA) and kept at the UCSD animal facility for a week before performing experiments. The major component of diabetes susceptibility in NOD/ShiLtJ (NOD) mice is the unique MHC haplotype, $H 2^{g 7}=\mathrm{K}^{\mathrm{d}}-\mathrm{Aa}^{\mathrm{d}}-\mathrm{Ab}^{\mathrm{g} 7}-\mathrm{E}^{\text {null }}-\mathrm{D}^{\mathrm{b}}$, that is linked to defects in antigen presenting processes, T-cell regulation, cytokine production, and wound healing (Fan et al. 2004). In brief, M $\phi$ s were harvested by lavage and incubated in the presence of Fluorescein isothiocyanate (FITC)-conjugated IgG-opsonized $S$. aureus as previously described (Vega and De Maio 2005). Phagocytosis was quantified by fluorometry (Fig. 1a) or visualized by fluorescent microscopy (Fig. 1b). We observed that both 


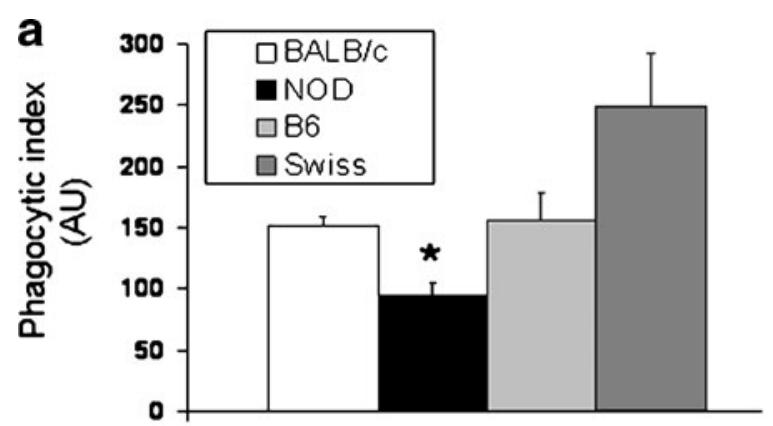

b

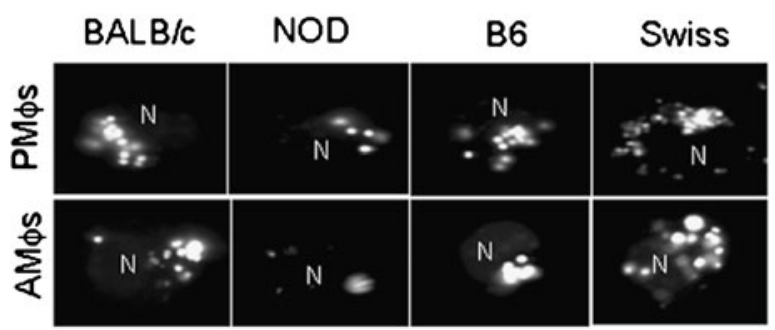

C

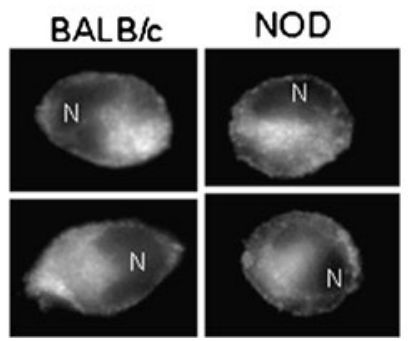

d

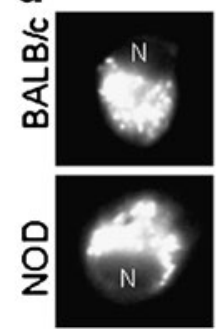

e

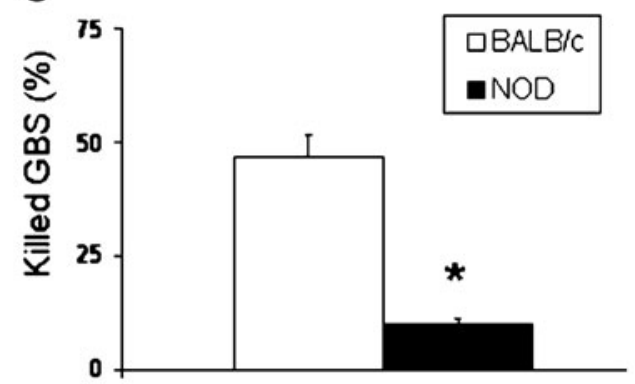

f

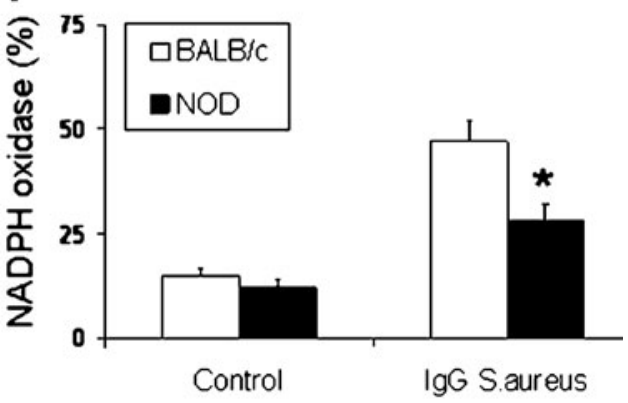

g

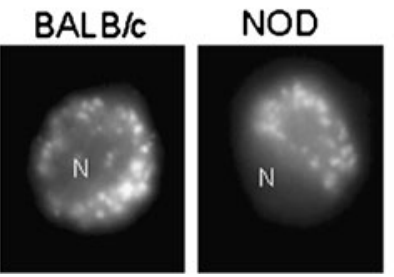

Fig. 1 NOD-derived M $\phi s$ displayed decreased phagocytic and killing activities. Female NOD/ShiLtJ mice ( 8 weeks old) were at the prediabetic stage, measured as normal random blood glucose levels $(\geq 250 \mathrm{mg} / \mathrm{ml}$ ). No differences were observed in body weights between the strains. Peritoneal (PMфs) and alveolar (AM $\phi s)$ macrophages were isolated by peritoneal or alveolar lavage and cultured for $16 \mathrm{~h}$ in RMPI1640 media (glucose level, 2,000 mg/L) supplemented with $10 \%$ FBS. Phagocytic assays were performed as described in Vega and De Maio (2005). In brief, cells $\left(5 \times 10^{5}\right.$ cells/well) were pre-incubated (30 min) with serum-free (SF) medium before the addition of FITC IgG-opsonized Staphylococcus aureus suspension $(70 \mu \mathrm{g} / \mathrm{ml}, 60 \mathrm{~min})$. Non-internalized bacteria were removed by washing with acidic PBS (pH 5.0). a Quantification of phagocytosis by fluorometry. Results were rectified by the number of live cells measured as MTT and expressed as arbitrary units (AU). $n=5$ mice in each group, experiments were performed in triplicate. Statistical analysis was performed by one-way analysis of variance (ANOVA) followed by Newman-Keuls test. * $p<0.01$ with respect to non-diabetic strains. b Visualization of internalized FITC IgG-opsonized Staphylococcus aureus. Phagocytic assay was performed as described above then cells were fixed in 4\% PFA, and visualization of internalized particles was performed using a fluorescent microscope. A representative experiment is presented. c Non-permeabilized cell surface immunostaining of Fc $\gamma$ Rs using a commercial FITC-conjugated antibody. d Endocytosis of AlexaFluor594-conjugated transferrin was performed as described by Vega et al. (2010). In brief, M $\phi s\left(5 \times 10^{5}\right.$ cells/well) were pre-incubated in SF medium (30 min) before adding AF594-transferrin $(50 \mu \mathrm{g} / \mathrm{ml}, 30 \mathrm{~min})$. Internalized signal was visualized by fluorescent microscopy. A representative experiment is presented. e Killing assay was performed by incubating $\left(120 \mathrm{~min}\right.$ at $\left.37^{\circ} \mathrm{C}\right) \mathrm{PM} \phi \mathrm{s}$ in the presence of live GBS with a multiplicity of infection (MOI) of 1 (one M $\phi$ per one GBS). Quantification of surviving bacteria was performed as described by Crotty Alexander et al. (2010), and results are expressed as percentage of killed bacteria. f Quantification of NADPH oxidase activation. The percentage of NADPH oxidase activity was estimated by incubating PM $\phi$ s with NBT in the presence or the absence of DPI, an inhibitor of NADPH oxidase as described previously (Vega and De Maio 2005). FITC IgG-opsonized Staphylococcus aureus $(70 \mu \mathrm{g} / \mathrm{ml})$ were incubated for $1.5 \mathrm{~h}$ after NBT incubation and NBT oxidation by superoxide anion was monitored at $540 \mathrm{~nm}$ and normalized by the protein content in each sample. The percentage of NADPH activation was calculated by subtracting the NBT plus DPI value from the NBT value. Results are expressed as the activity of NADPH oxidase (percentage of total superoxide anion production). $n=$ 5 mice in each group, experiments were performed in triplicate. Statistical analysis was performed by one-way analysis of variance (ANOVA) followed by Newman-Keuls test. ${ }^{*} p<0.01$ with respect to non-diabetic strain. g Visualization of lysosomes labeled with Lysotraker-red (Invitrogen) in PM $\phi$ s derived from BALB/c and NOD mice. A representative experiment is presented 
$\mathrm{AM} \phi \mathrm{s}$ and $\mathrm{PM} \phi \mathrm{s}$ derived from NOD mice internalized significantly lower amounts of fluorescent IgG-opsonized S. aureus when compared with cells isolated from nondiabetic strains (Fig. 1a, b). It is important to remark that at 8 weeks of age, NOD female mice are at the pre-diabetic stage characterized by normal random blood glucose levels $(\geq 250 \mathrm{mg} / \mathrm{dl})$, with a body weight that does not differ from that observed in non-diabetic animals. On the contrary, these animals have altered glucose tolerance as well as insulinemia (Amrani et al. 1998). Spontaneous onset of DMT1 had been observed in $80 \%$ of NOD female mice ( $\geq 12$ weeks old), which is characterized by elevated random blood glucose levels $(\leq 250 \mathrm{mg} / \mathrm{dl})$. Thus, our observations showed that M $\phi$ s derived from female diabetic NOD mice (14 weeks old) also had a lower phagocytic capacity in comparison with cells isolated from BALB/c mice (35 and $101 \mathrm{AU}$, respectively), suggesting that decreased phagocytosis in NOD cells is independent of the blood glucose levels or the stage of the disease. Lower phagocytic capacity by NOD-derived cells was observed independently of the nature of the ligand or the presence or absence of opsonins. NOD-reduced phagocytosis was not due to a diminished expression of the FcyRs on the cell surface (Fig. 1c) or to a decreased binding capacity, suggesting that processes such as phagosome formation and/or maturation may be responsible for this NOD phenotype. Interestingly, we observed no differences in endocytosis of transferrin (clathrin-mediated endocytosis) (Fig. 1d) or cholera toxin (lipid-mediated endocytosis) (data not shown), strongly indicating the presence of specific alterations in the activation of the NOD phagocytic signal transduction pathway. Diminished phagocytosis of NOD-derived M $\phi \mathrm{s}$ is linked to a 5.3-fold lower killing capacity of live group B Streptococcus (GBS) (Fig. 1e) and a deficient production of superoxide anion by the NADPH oxidase (Fig. 1f). No difference in the amount of lysosomes (measured by Lysotraker-red staining) were observed between NOD and non-diabetic M $\phi$ s (Fig. 1g), although we cannot discard the existence of differences in enzymatic activities that may be responsible for this diminished killing. In summary, our data shows that M $\phi$ s derived from NOD mice have decreased (compromised) phagocytic and killing responses. These alterations may be responsible for the increased susceptibility to recurrent and more prolonged infections in diabetic patients. Similarly, it has been shown that NOD mice required more time to resolve experimentally induced inflammatory processes and infections (Rich and Lee 2005; Bouma et al. 2005). The precise mechanism(s) involved in this depressed response remains unclear. Maree et al. (2005, 2008) have suggested that a combination between a low rate of engulfment (phagosome formation) and diminished particle digestion are responsible for the decreased clearance of AC by diabetic Mos. Fan et al. (2006) linked deficient activation of small Rho GTPases, such as CdC42 and Rac, to altered cytoskeleton rearrangements in major murine models of spontaneous autoimmunity. In addition to these alterations, NOD mice show an impaired recruitment of professional phagocytes in response to local inflammation (Bouma et al. 2005), which is associated with a deficient production of local chemokines and an increased secretion of IL-10. Moreover, it has been shown that neutrophils derived from diabetic patients have decreased bactericidal activity, resulting in further delays in pathogen destruction and, therefore, delays in the tissue repair and wound healing processes (Delamaire et al. 1997; Naghibi et al. 1987).

NOD-derived M $M$ s express significantly higher levels of IL10 in response to pro-inflammatory stimuli Previous reports have shown that in diabetic individuals there is a defective clearance of AC by M $\phi$ s (Trudeau et al. 2000; Mathis et al. 2001). Moreover, in M $\phi$ s derived from NOD mice, it has been reported that, together with the impaired phagocytosis of AC (O'Brien et al. 2006), an abnormal production of IL12 (Rainbow et al. 2008), IL-21 (King et al. 2004), and IL$1 \beta$ (Bouma et al. 2005) also occurs. It is important to remark that quantitative and kinetic balance of pro- and antiinflammatory mediators contributes to restoring immunological homeostasis and determines the final outcome of biological processes (Brown et al. 2003). Thus, we investigated potential alterations in cytokine production by NOD $\mathrm{M} \phi \mathrm{s}$ in response to pro-inflammatory stimuli such as bacteria particles or lipopolysaccharide (LPS). In brief, PM $\phi$ s derived from NOD and non-diabetic (BALB/c) mice were incubated in the presence and absence of LPS or FITC IgG-opsonized E. coli, and production of cytokines was evaluated by qRTPCR and ELISA (Fig. 2). We observed that non-stimulated cells (control) have similar and extremely low levels of IL10 and tumor necrosis factor alpha (TNF- $\alpha$ ). FITC IgGopsonized E. coli activation of NOD-derived PM $\phi$ s resulted in a significantly higher induction of IL-10 when compared to BALB/c-derived cells (Fig. 2a). Similar results were observed when PM $\phi$ s were incubated with LPS $(100 \mathrm{ng} / \mathrm{ml}$, $2 \mathrm{~h})$ or zymozan $(200 \mu \mathrm{g} / \mathrm{ml}, 2 \mathrm{~h}$ ) (data not shown), suggesting that increased production of IL-10 is a common phenomenon after activation of CD14/TLR4 (by LPS), FcyR (by IgG-opsonized E. coli) or TLR2/TLR6 (by zymozan) pathways. No differences in the levels of these receptors (Figs. 1c and 2e, f) were observed between NOD and $\mathrm{BALB} / \mathrm{c}$ derived cells, suggesting that another mechanism is responsible for the larger production of IL-10. Interestingly, activation of $\mathrm{M} \phi \mathrm{s}$ with these pro-inflammatory ligands resulted in similar induction of TNF- $\alpha$ (Fig. 2b, c). Thus, calculated TNF- $\alpha / \mathrm{IL}-10$ ratios were significantly lower (7.8-fold) in NOD-derived M $\phi$ s, suggesting a strong anti-inflammatory component in response to proinflammatory stimuli (Fig. 2d). It is important to remark 

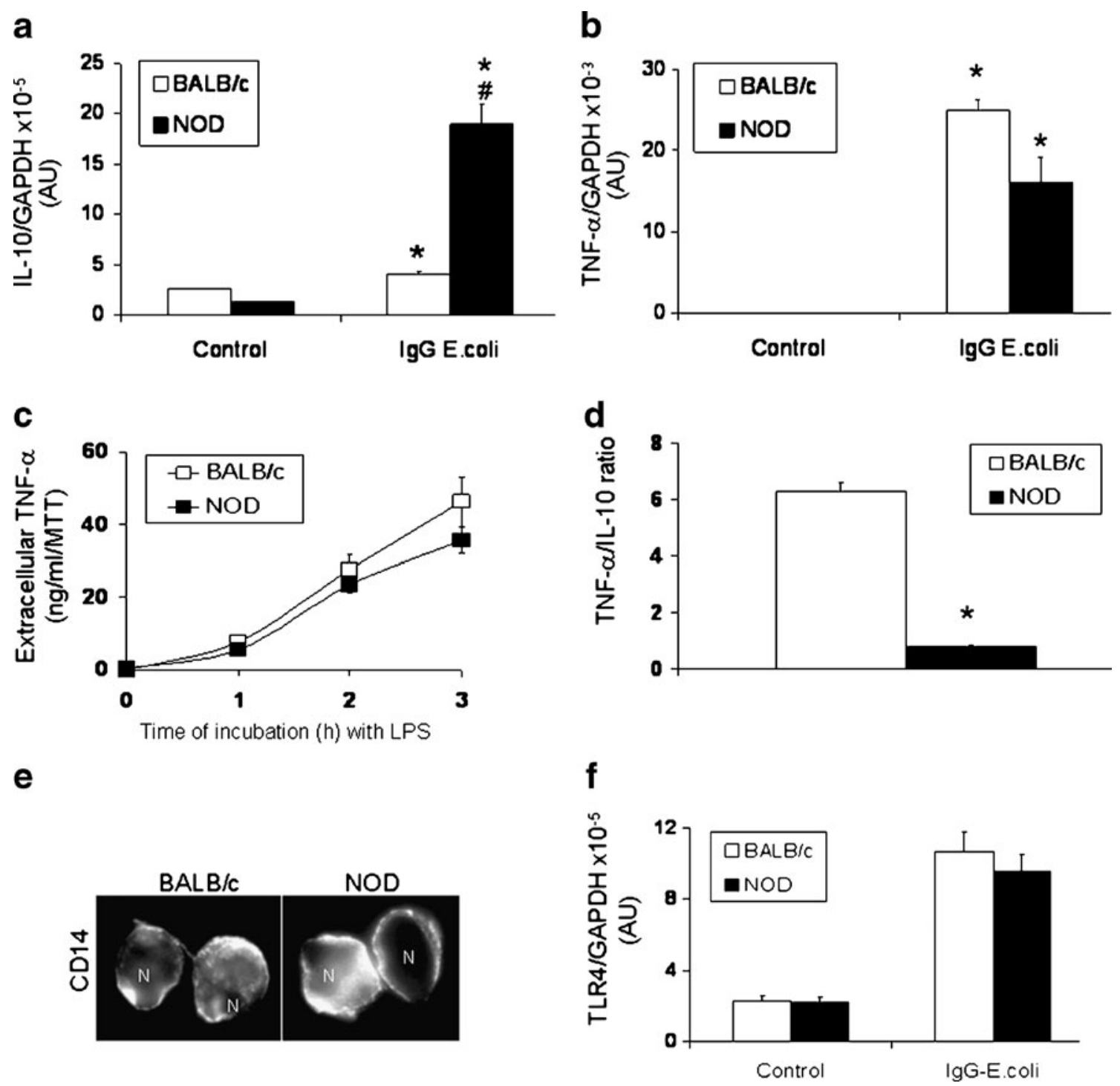

Fig. 2 NOD-derived M $\phi$ s respond to pro-inflammatory stimuli with a strong induction of IL-10. PM $\phi s\left(2.5 \times 10^{5}\right.$ cells/well $)$ derived from NOD or $\mathrm{BALB} / \mathrm{c}$ mice (female, 8 weeks old) were pre-incubated in SF medium (30 min) and then IgG-opsonized Escherichia coli particles $(70 \mu \mathrm{g} / \mathrm{ml})$ were added $(60 \mathrm{~min})$. Total RNA was isolated using Trizol. cDNA was produced using random primers, and levels of IL-10 (a) and TNF- $\alpha$ (b) were measured by qRT-PCR. Results are expressed as number of copies of each cytokine messenger rectified by number of copies of GAPDH levels. c Detection of TNF- $\alpha$ in the extracellular medium by ELISA. PM $\phi s\left(5 \times 10^{6}\right.$ cells/well $)$ were incubated in complete medium in the presence of LPS $(100 \mathrm{ng} / \mathrm{ml})$ for 1,2 , and

3 h. Extracellular medium was collected. TNF- $\alpha$ levels were measured and rectified by MTT values in each well. d Calculated TNF- $\alpha / \mathrm{IL}-10$ ratios in response to IgG-conjugated Escherichia coli particles incubation. These ratios were calculated from data presented in $\mathbf{a}$ and $\mathbf{b}$. e CD14 immunostaining using non-permeabilized PM $\phi$ s derived from $\mathrm{NOD}$ and BALB/c mice. Immunostaining was performed as described in Vega and De Maio (2003). f TLR4 expression measured by qRTPCR. $n=5$ mice in each group, experiments were performed in triplicate. Statistical analysis was performed by one-way analysis of variance (ANOVA) followed by Newman-Keuls test. ${ }^{*} p<0.01$, with respect to control BALB/c. ${ }^{\#} p<0.01$, with respect to control stimulated BALB/c

that other non-diabetic strains, such as Swiss and DBA, have similar responses to those observed in BALB/c M $\phi$ s. These data demonstrate abnormal regulation of the IL-10 pathway in NOD-derived M $\phi s$, which results in a large expression of this cytokine in response to pro-inflammatory stimuli. The mechanisms that control this unusual expression of IL-10 remain unknown and require further investigation. Excessive or mistimed IL-10 synthesis is linked to a down-regulation of the inflammatory response to the extent that pathogens escape

immune control, resulting in chronic non-healing or recurrent infections. For example, transgenic mice that constitutively over-express IL-10 are highly susceptible to infections (Groux et al 1999; Feng et al. 2002), and elevated levels of IL-10 observed in several autoimmune diseases are linked to the occurrence of recurrent infections (Hedrich and Bream 2010; Ishida et al. 1994; Sanjabi et al. 2009). Although the association between IL-10 and autoimmunity is well documented, the mechanisms that explain how elevated levels of 
this cytokine promote autoimmunity are not fully understood. Years of investigation have suggested that the effects of IL-10 on $\mathrm{B}$ cell function play a critical role in the onset of autoimmunity by stabilizing auto-reactive clones, prolonging B cell survival, differentiation, proliferation, and antibody production (Lalani et al. 1997; Moore et al. 2001; te Velde et al. 1992; Levy and Brouet 1994; Llorente et al. 1995).

a

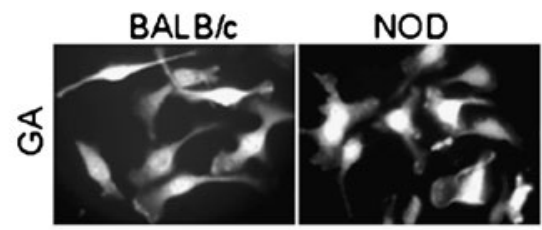

b

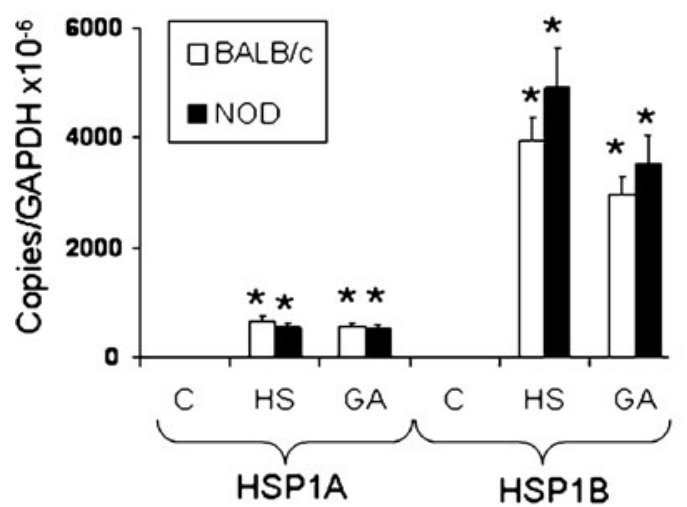

C

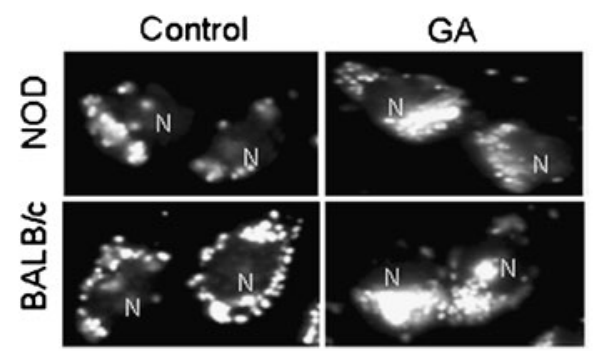

Expression of hsp reverts the NOD-phenotype by improving phagocytosis and killing activities We have previously reported that induction of hsp results in increased phagocytosis by $\mathrm{J} 774$ cells, which depends on the synthesis of new proteins (Vega and De Maio 2005). The mechanisms responsible for this increase remain unknown, although our investigations strongly suggest a critical role of Hsp70 (Vega et al. 2010). e
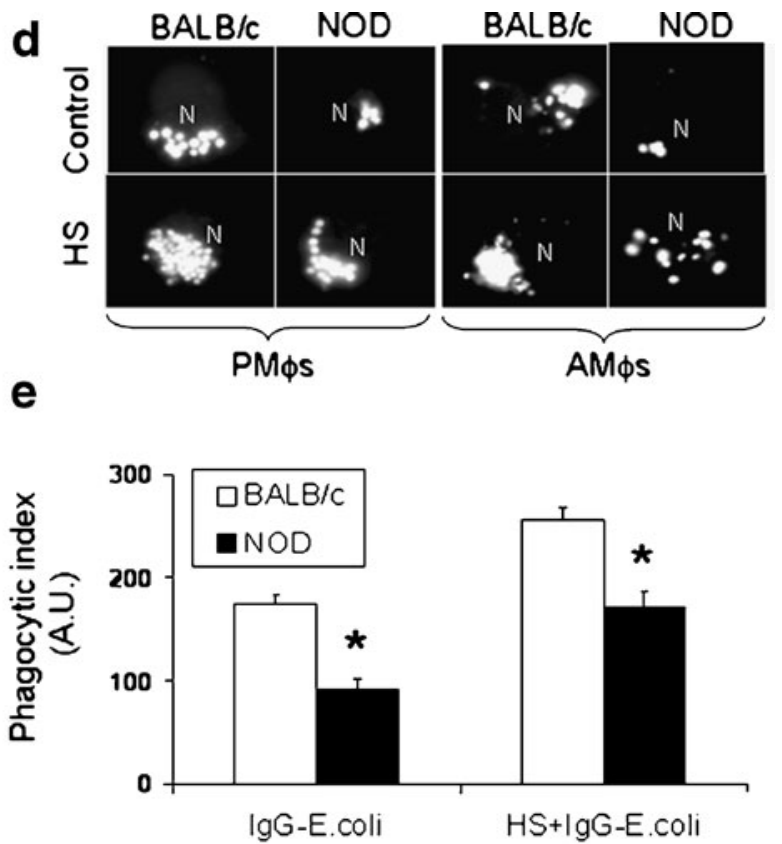

f

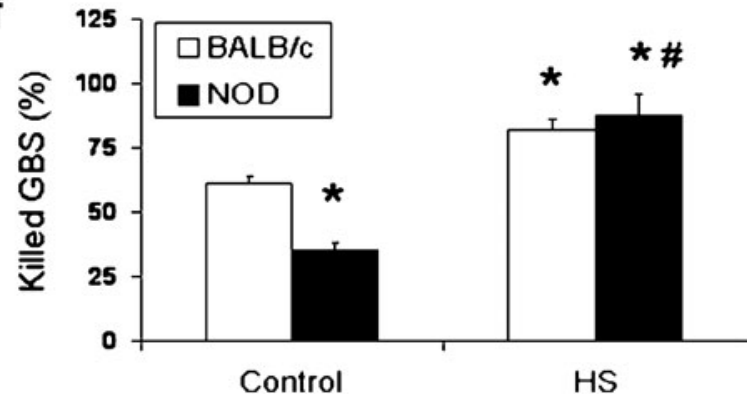

FITC-conjugated IgG-opsonized Staphylococcus aureus particles. Cells were either incubated in the presence or absence of GA $(1 \mu \mathrm{g} /$ $\mathrm{ml}, 3 \mathrm{~h})(\mathbf{c})$ or subjected or not to HS (d) and then visualization of internalized FITC-conjugated IgG-opsonized Staphylococcus aureus was performed by fluorescent microscopy. (e) Phagocytic indexes were measured by fluorometry as described in Fig. 1 using PM $\phi s$ derived from NOD and BALB/c mice (f) PM $\phi$ s were subjected to HS and allowed to recover for $24 \mathrm{~h}$, and then cells were incubated with live GBS at an MOI of $1\left(3 \mathrm{~h}\right.$ at $\left.37^{\circ} \mathrm{C}\right)$. Surviving bacteria colonies were enumerated as described in Fig. 1. Results are expressed as percentage of killed bacteria. $n=5$ mice in each group, experiments were performed in triplicate. Statistical analysis was performed by one-way analysis of variance (ANOVA) followed by Newman-Keuls test. $* p<0.01$ with respect to $\mathrm{BALB} / \mathrm{c}$ control (non-heat shocked) cells. ${ }^{\#} p<0.01$ with respect to NOD control (non-heat shocked) cells 
Thus, we decided to evaluate if the activation of the heat shock response (HSR) may compensate for the genetic or epigenetic alterations associated with the NOD phenotype. To accomplish this possibility, $\mathrm{AM} \phi \mathrm{s}$ and $\mathrm{PM} \phi \mathrm{s}$ derived from NOD and $\mathrm{BALB} / \mathrm{c}$ mice were submitted to heat shock (HS) $\left(42^{\circ} \mathrm{C}\right.$, $90 \mathrm{~min}$ ) or incubated with geldanamycin (GA, $1 \mu \mathrm{g} / \mathrm{ml})$, a specific Hsp90 inhibitor, as previously described (Vega and De Maio 2005). GA treatment activates the HSR by disrupting the Hsp90/heat shock factor-1 (HSF-1) complex. Then, trimerarized HSF-1 translocates to the nucleus and initiates hsp gene transcription. We observed that NOD and $\mathrm{BALB} / \mathrm{c}$ derived $\mathrm{M} \phi \mathrm{s}$ express comparable levels of Hsp70 in response to GA treatment (Fig. 3a) or to HS (Fig. 3b). Although both HSP1A and HSP1B are strongly up-regulated in comparison with control (resting) cells, a significantly higher induction of HSP1B was reported in response to HS as well as GA treatment (Fig. 3b). HSP1B expression has been implicated in the increased survival of Fc $\gamma R$-activated M $\phi s$ (Smith et al. 2010) and its expression regulates the induction of pro- (IL-1 $\beta$ ) and anti- (IL-10) inflammatory cytokines. Our data show that treatment with GA (Fig. 3c) as well as HS/recovery (Fig. 3d) results in significant increases in phagocytosis of FITC-conjugated IgG-opsonized S. aureus by both NOD and BALB/c derived M $\phi s$. HS-mediated phagocytic enhancement in non-diabetic cells is larger than that observed in NOD-M $\phi$ s (Fig. 3e). Although it is important to remark that activation of HSR in heat-shocked NOD-M $\phi s$ resulted in phagocytic indexes that are similar to those observed in non-heat-shocked (control) non-diabetic cells exposed to bacteria particles (Fig. 3e). These data demonstrate that NOD-M $\phi$ s subjected to HS display similar phagocytic capacity to that observed in non-diabetic (control) cells. This HS-mediated improvement may result in significant improvements in the mounting of the inflammatory response in vivo in diabetic individuals. Moreover, HS also resulted in a significant increase in the killing capacity of $\mathrm{PM} \phi \mathrm{s}$ derived from NOD mice, to levels that did not differ from those reached by BALB/c-derived heat-shocked PM $\phi s$ (Fig. 3f). The mechanisms associated with these observations are under investigation. Although we must highlight that HS did not prevent the NOD-associated increased expression of IL-10 or revert the abnormally low production of superoxide anion by the NADPH oxidase in response to proinflammatory ligands, suggesting that activation of other pathways are responsible for the modification of NOD phenotype by HS. Unpublished data from our laboratory strongly suggests that HS improves the killing capacity of $\mathrm{PM} \phi \mathrm{s}$ by up-regulating the expression of antimicrobial peptides and iNOS (Vega and Crotty Alexander, unpublished data). The mechanisms by which hsp expression modulates the inflammatory response of professional phagocytes may also be related to the control of vesicle trafficking and/or cytoskeleton rearrangements. Previous reports have shown
F-actin formation after HS (Vega and De Maio 2005; Collier and Schlesinger 1986; Han et al. 2000) as well as a close association of Hsp70 with actin-filaments, microtubules, tubulin, and intermediate filaments (Kirby et al. 1994; Liao et al. 1995; Dou et al. 2003). Small hsp, in particular Hsp27, have also been implicated in the regulation of the cytoskeleton by participating in F-actin formation around plasma membrane rufflings and pinocytosis (Lavoie et al. 1993) and by inducing stabilization of actin filaments (Piotrowicz and Levin 1997). Another potential explanation may be related to the capacity of hsp, more specifically Hsp70, to interact with membranes (Vega et al. 2008; Arispe et al. 2002, 2004; Multhoff et al. 1995), which may provide a modulatory effect over key processes such as vesicle formation, fusion, and/or recycling, as well as membrane fluidity. These changes may control phagosome movements, assembling of protein complexes (i.e., receptors) on the membrane as well as targeting key proteins to required cellular compartments. Finally, we cannot discard the contribution of the classic cytoprotective role of hsp, as these proteins may play a critical role during $\mathrm{M} \phi$ activation by stabilizing cell structures (i.e., phagosomes and lysosomes) and therefore allowing clearance and destruction of pathogens and/or damaged cells (Morimoto 1991; Xu and Wick 1996), as well as protecting key newly synthesized pro- and anti-inflammatory polypeptides from damage.

\section{Conclusions}

Our data show the capacity of the HSR to up-regulate phagocytosis and killing activities in both diabetic and nondiabetic cells. We propose that these increases are part of the stress response, whose final goal is to eliminate necrotic cells, cell debris, and infectious agents with minimal tissue damage. In DMT1 individuals, as well as other patients with compromised function of professional phagocytes, activation of HSR may compensate for genetic or epigenetic dysfunction in professional phagocytes resulting in significant improvements in their response to injury or to infections.

Acknowledgments Authors would like to thank Dr. Antonio De Maio (UCSD) and Dr. Victor Nizet (UCSD) for their support and mentoring. We also thank Molly Wofford for editing this manuscript. This work was supported by an University of California Academic Senate research grant (SUR127H) and by Dr. Crotty Alexander's Biomedical Research Fellowship from The Hartwell Foundation.

\section{References}

Amrani A, Durant S, Throsby M, Coulaud J, Dardenne M, HomoDelarche F (1998) Glucose homeostasis in the nonobese diabetic mouse at the prediabetic stage. Endocrinology 139(3):1115-1124 
Arispe N, Doh M, De Maio A (2002) Lipid interaction differentiates the constitutive and stress-induced heat shock proteins Hsc70 and Hsp70. Cell Stress Chaperones 7(4):330-338

Arispe N, Doh M, Simakova O, Kurganov B, De Maio A (2004) Hsc70 and Hsp70 interact with phosphatidylserine on the surface of PC12 cells resulting in a decrease of viability. FASEB J 18 (14):1636-1645

Asea A, Kabingu E, Stevenson MA, Calderwood SK (2000) HSP70 peptidembearing and peptide-negative preparations act as chaperokines. Cell Stress Chaperones 5(5):425-431

Asea A, Rehli M, Kabingu E, Boch JA, Bare O, Auron PE, Stevenson MA, Calderwood SK (2002) Novel signal transduction pathway utilized by extracellular HSP70: role of toll-like receptor (TLR) 2 and TLR4. J Biol Chem 277(17):15028-15034

Bagley J, Tian C, Iacomini J (2008) Prevention of type 1diabetes in NOD mice by genetic engineering of hematopoietic stem cells. Methods Mol Biol 433:277-285

Basu S, Binder RJ, Ramalingam T, Srivastava PK (2001) CD91 is a common receptor for heat shock proteins gp96, hsp90, hsp70, and calreticulin. Immunity 14(3):303-313

Benhamou PY, Mullen Y, Clare-Salzler M, Sangkharat A, Benhamou C, Shevlin L, Go VL (1995) Essential fatty acid deficiency prevents autoimmune diabetes in nonobese diabetic mice through a positive impact on antigen-presenting cells and Th2 lymphocytes. Pancreas 11(1):26-37

Bouma G, Nikolic T, Coppens JM, van Helden-Meeuwsen CG, Leenen PJ, Drexhage HA, Sozzani S, Versnel MA (2005) NOD mice have a severely impaired ability to recruit leukocytes into sites of inflammation. Eur J Immunol 35(1):225-235

Brown JR, Goldblatt D, Buddle J, Morton L, Thrasher AJ (2003) Diminished production of anti-inflammatory mediators during neutrophil apoptosis and macrophage phagocytosis in chronic granulomatous disease (CGD). J Leukoc Biol 73:591-599

Collier NC, Schlesinger MJ (1986) The dynamic state of heat shock proteins in chicken embryo fibroblasts. J Cell Biol 103:14951507

Crotty-Alexander LE, Maisey HC, Timmer AM, Rooijakkers SHM, Gallo RL, von Köckritz-Blickwede M, Nizet V (2010) M1T1 group A streptococcal pili promote epithelial colonization but diminish systemic virulence through neutrophil extracellular entrapment. J Mol Med 88:371-881

De Maio A (1999) Heat shock proteins: facts, thoughts, and dreams. Shock 11(1):1-12

De Maio A (2010) Extracellular heat shock proteins, cellular export vesicles, and the stress observation system: a form of communication during injury, infection, and cell damage: it is never known how far a controversial finding will go! Dedicated to Ferruccio Ritossa. Cell Stress Chaperones 101(2):294-301

Delamaire M, Maugendre D, Moreno M, Le Goff MC, Allannic H, Genetet B (1997) Impaired leucocyte functions in diabetic patients. Diabet Med 14(1):29-34

Donnelly TJ, Sievers RE, Vissern FL, Welch WJ, Wolfe CL (1992) Heat shock protein induction in rat hearts. A role for improved myocardial salvage after ischemia and reperfusion? Circulation 85(2):769-778

Dou F, Netzer WJ, Tanemura K, Li F, Hartl FU, Takashima A, Gouras GK, Greengard P, Xu H (2003) Chaperones increase association of protein with microtubules. Proc Natl Acad Sci USA 100:721726

Fan H, Longacre A, Meng F, Patel V, Hsiao K, Koh JS, Levine JS (2004) Cytokine dysregulation induced by apoptotic cells is a shared characteristic of macrophages from nonobese diabetic and systemic lupus erythematosus-prone mice. J Immunol 172 (8):4834-4843

Fan H, Patel VA, Longacre A, Levine JS (2006) Abnormal regulation of the cytoskeletal regulator Rho typifies macrophages of the major murine models of spontaneous autoimmunity. J Leukoc Biol 79(1):155-165

Feng CG, Kullberg MC, Jankovic D, Cheever AW, Caspar P, Coffman RL (2002) Transgenic mice expressing human interleukin-10 in the antigen-presenting cell compartment show increased susceptibility to infection with Mycobacterium avium associated with decreased macrophage effector function and apoptosis. Infect Immun 70:6672-6679

Giffard RG, Han RQ, Emery JF, Duan M, Pittet JF (2008) Regulation of apoptotic and inflammatory cell signaling in cerebral ischemia: the complex roles of heat shock protein 70. Anesthesiology 109 (2):339-348

Gordon S, Taylor PR (2005) Monocyte and macrophage heterogeneity. Nat Rev Immunol 5(12):953-964

Groux H, Cottrez F, Rouleau M, Mauze S, Antonenko S, Hurst S (1999) A transgenic model to analyze the immunoregulatory role of IL-10 secreted by antigen-presenting cells. J Immunol 162:1723-1729

Han SI, Ha KS, Kang KI, Kim HD, Kang HS (2000) Heat shockinduced actin polymerization, SAPK/JNK activation, and heatshock protein expression are mediated by genistein-sensitive tyrosine kinase(s) in K562 cells. Cell Biol Int 24:447-457

Hedrich CM, Bream JH (2010) Cell type-specific regulation of IL-10 expression in inflammation and disease. Immunol Res 47(13):185-206

Hutchings P, Rosen H, O'Reilly L, Simpson E, Gordon S, Cooke A (1990) Transfer of diabetes in mice prevented by blockade of adhesion-promoting receptor on macrophages. Nature 348 (6302):639-642

Ishida H, Muchamuel T, Sakaguchi S, Andrade S, Menon S, Howard M (1994) Continuous administration of anti-interleukin 10 antibodies delays onset of autoimmunity in NZB/WF1 mice. J Exp Med 179(1):305-310

Jun HS, Yoon CS, Zbytnuik L, van Rooijen N, Yoon JW (1999) The role of macrophages in T cell-mediated autoimmune diabetes in nonobese-diabetic mice. J Exp Med 189(2):347-358

King C, Ilic A, Koelsch K, Sarvetnick N (2004) Homeostatic expansion of $\mathrm{T}$ cells during immune insufficiency generates autoimmunity. Cell 117(2):265-277

Kirby BA, Merril CR, Ghanbari H, Wallace WC (1994) Heat shock proteins protect against stress-related phosphorylation of tau in neuronal PC12 cells that have acquired thermotolerance. J Neurosci 14:5687-5693

Lalani I, Bhol K, Ahmed AR (1997) Interleukin-10: biology, role in inflammation and autoimmunity. Ann Allergy Asthma Immunol 79:469-483

Lavoie JN, Gingras-Breton G, Tanguay RM, Landry J (1993) Induction of Chinese hamster HSP27 gene expression in mouse cells confers resistance to heat shock: HSP27 stabilization of the microfilament organization. J Biol Chem 268:3420-3429

Levy Y, Brouet JC (1994) Interleukin-10 prevents spontaneous death of germinal center B cells by induction of the bcl-2 protein. $\mathrm{J}$ Clin Invest 93:424-428

Liao J, Lowthert LA, Ghori N, Omary MB (1995) The 70-kDa heat shock proteins associate with glandular intermediate filaments in an ATP-dependent manner. J Biol Chem 270:915-922

Lindquist S, Craig EA (1988) The heat-shock proteins. Annu Rev Genet 22:631-677

Llorente L, Zou W, Levy Y (1995) Role of interleukin 10 in the B lymphocyte hyperactivity and autoantibody production of human systemic lupus erythematosus. J Exp Med 181:839-844

Maree AF, Komba M, Dyck C, Labecki M, Finegood DT, Edelstein-Keshet L (2005) Quantifying macrophage defects in type 1 diabetes. J Theor Biol 233(4):533-551

Marée AF, Komba M, Finegood DT, Edelstein-Keshet L (2008) A quantitative comparison of rates of phagocytosis and digestion of 
apoptotic cells by macrophages from normal (BALB/c) and diabetes-prone (NOD) mice. J Appl Physiol 104(1):157-169

Mathis D, Vence L, Benoist C (2001) Beta-cell death during progression to diabetes. Nature 414(6865):792-798

Mohammad MK, Morran M, Slotterbeck B, Leaman DW, Sun Y, Grafenstein H, Hong SC, McInerney MF (2006) Dysregulated Toll-like receptor expression and signaling in bone marrowderived macrophages at the onset of diabetes in the non-obese diabetic mouse. Int Immunol 18(7):1101-1113

Moore KW, de Waal Malefy TR, Coffman RL (2001) Interleukin-10 and the interleukin-10 receptor. Annu Rev Immunol 19:683-765

Morimoto RI (1991) Heat shock: the role of transient inducible responses in cell damage, transformation, and differentiation. Cancer Cells 3(8):295-301

Multhoff G, Botzler C, Wiesnet M, Müller E, Meier T, Wilmanns W, Issels RD (1995) A stress-inducible 72-kDa heat-shock protein (HSP72) is expressed on the surface of human tumor cells, but not on normal cells. Int J Cancer 61(2):272-279

Naghibi M, Smith RP, Baltch AL, Gates SA, Wu DH, Hammer MC, Michelsen PB (1987) The effect of diabetes mellitus on chemotactic and bactericidal activity of human polymorphonuclear leukocytes. Diabetes Res Clin Pract 4(1):27-35

O'Brien BA, Geng X, Orteu CH, Huang Y, Ghoreishi M, Zhang Y, Bush JA, Li G, Finegood DT, Dutz JP (2006) A deficiency in the in vivo clearance of apoptotic cells is a feature of the NOD mouse. J Autoimmun 26(2):104-115

Piotrowicz RS, Levin EG (1997) Basolateral membrane-associated 27$\mathrm{kDa}$ heat shock protein and microfilament polymerization. J Biol Chem 272:25920-25927

Pozzilli P, Leslie RD (1994) Infections and diabetes: mechanisms and prospects for prevention. Diabet Med 11(10):935-941

Rainbow DB, Esposito L, Howlett SK, Hunter KM, Todd JA, Peterson LB, Wicker LS (2008) Commonality in the genetic control of Type 1 diabetes in humans and NOD mice: variants of genes in the IL-2 pathway are associated with autoimmune diabetes in both species. Biochem Soc Trans 36(Pt 3):312-315

Rich J, Lee JC (2005) The pathogenesis of Staphylococcus aureus infection in the diabetic NOD mouse. Diabetes 54(10):2904-2910

Sanjabi S, Zenewicz LA, Kamanaka M, Flavell RA (2009) Antiinflammatory and pro-inflammatory roles of TGF-beta, IL-10, and IL-22 in immunity and autoimmunity. Curr Opin Pharmacol 9(4):447-453

Shultz LD, Schweitzer PA, Christianson SW, Gott B, Schweitzer IB, Tennent B, McKenna S, Mobraaten L, Rajan TV, Greiner DL (1995) Multiple defects in innate and adaptive immunologic function in NOD/LtSz-scid mice. J Immunol 154(1):180-191

Smith KJ, Twal WO, Soodavar F, Virella G, Lopes-Virella MF, Hammad SM (2010) Heat shock protein 70B' (HSP70B') expression and release in response to human oxidized low density lipoprotein immune complexes in macrophages. J Biol Chem 285(21):15985-15993

te Velde AA, de Waal Malefijt R, Huijbens RJ (1992) IL-10 stimulates monocyte $\mathrm{Fc}$ gamma $\mathrm{R}$ surface expression and cytotoxic activity. Distinct regulation of antibody-dependent cellular cytotoxicity by IFN-gamma, IL-4, and IL-10. J Immunol 149:4048-4052

Trudeau JD, Dutz JP, Arany E, Hill DJ, Fieldus WE, Finegood DT (2000) Neonatal beta-cell apoptosis: a trigger for autoimmune diabetes? Diabetes 49(1):1-7

Vega VL, De Maio A (2003) Geldanamycin treatment ameliorates the response to LPS in murine macrophages by decreasing CD14 surface expression. Mol Biol Cell 14(2):764-773

Vega VL, De Maio A (2005) Increase in phagocytosis after geldanamycin treatment or heat shock: role of heat shock proteins. J Immunol 175(8):5280-5287

Vega VL, Rodríguez-Silva M, Frey T, Gehrmann M, Diaz JC, Steinem C, Multhoff G, Arispe N, De Maio A (2008) Hsp70 translocates into the plasma membrane after stress and is released into the extracellular environment in a membrane-associated form that activates macrophages. J Immunol 180(6):4299-4307

Vega VL, Charles W, De Maio A (2010) A new feature of the stress response: increase in endocytosis mediated by Hsp70. Cell Stress Chaperones 15(5):517-527

Villar J, Edelson JD, Post M, Mullen JB, Slutsky AS (1993) Induction of heat stress proteins is associated with decreased mortality in an animal model of acute lung injury. Am Rev Respir Dis 147 (1):177-181

Xu Q, Wick G (1996) The role of heat shock proteins in protection and pathophysiology of the arterial wall. Mol Med Today 2 (9):372-379 